IR-08-015

\title{
Global and Regional Population Ageing: How Certain Are We of its Dimensions?
}

Wolfgang Lutz (lutz@iiasa.ac.at)

Warren Sanderson (wsanderson@notes.cc.sunysb.edu)

Sergei Scherbov (sergei.scherbov@oeaw.ac.at)

Approved by

Sten Nilsson

Acting Director (nilsson@iiasa.ac.at)

July 30, 2008 Institute, its National Member Organizations, or other organizations supporting the work. 


\section{Contents}

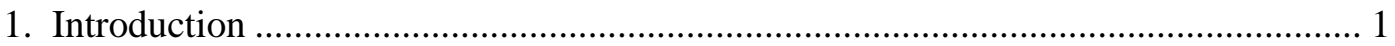

2. New Regional and Global Probabilistic Population Forecasts.................................. 2

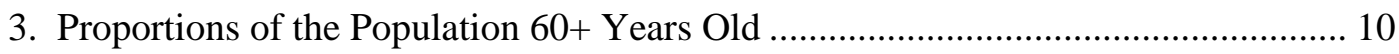

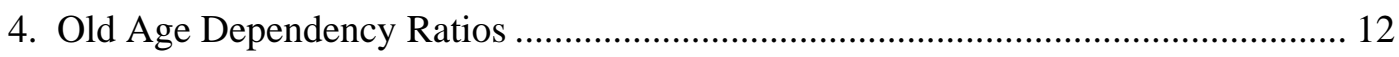

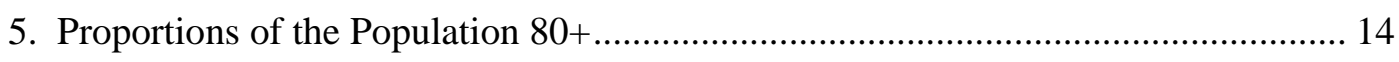

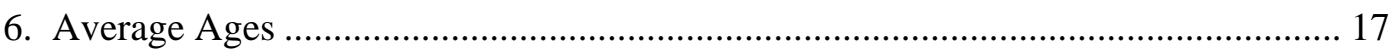

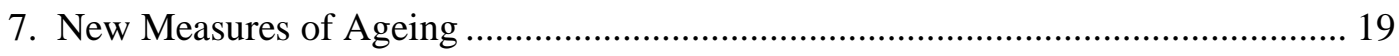

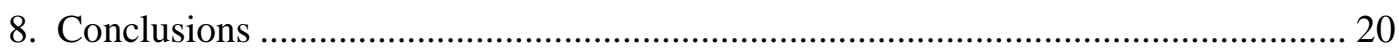

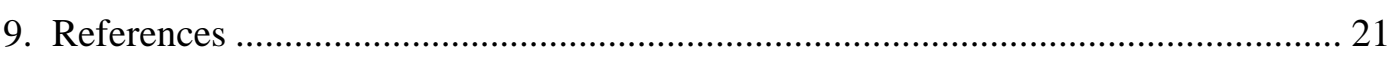

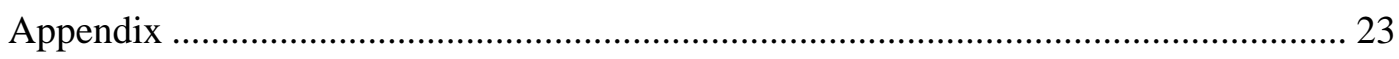




\begin{abstract}
Population ageing is, in the first instance, a demographic phenomenon, although its consequences go far beyond demography. But the future trends of ageing are not yet known and many of the consequences of ageing will depend on the future speed and extent of ageing. Here we summarize what is already known and what is not yet known about future ageing trends in different parts of the world. We do this through the means of new probabilistic population forecasts. Section 2 presents the results of those forecasts. They confirm our earlier finding that it is highly likely that the world's population growth will come to the end during this century. The following four sections present results for proportions of populations 60+, old age dependency ratios, proportions $80+$ and average ages. In Section 7, we analyse a new measure of ageing that takes life expectancy changes into account.
\end{abstract}




\section{About the Authors}

Wolfgang Lutz is Leader of the World Population Program, International Institute for Applied Systems Analysis (IIASA), Laxenburg, Austria; and Director, Vienna Institute of Demography of the Austrian Academy of Sciences.

Warren Sanderson is Co-Chair of the Department of Economics and Professor of History at the State University of New York at Stony Brook, and an Institute Scholar with the World Population Program at IIASA.

Sergei Scherbov is a Senior Research Scholar at IIASA's World Population Program and Research Group Leader at the Vienna Institute of Demography of the Austrian Academy of Sciences. 


\title{
Global and Regional Population Ageing: How Certain Are We of its Dimensions?
}

\author{
Wolfgang Lutz, Warren Sanderson, and Sergei Scherbov
}

\section{Introduction}

Population ageing has become an important social, economic, health and even cultural topic because of the magnitudes of its effects and its pervasiveness. Specific combinations of declining fertility and mortality trends have resulted in an accelerating speed of population ageing in most societies including developing countries (Lutz et al. 2008). Hence population ageing is in first instance a demographic phenomenon, although in its consequences it goes far beyond demography. But the future trends of ageing are not yet precisely known and many of the consequences of ageing will also depend on the future speed and extent of ageing. In this contribution we try to summarize what is already known and what is not yet known about future ageing trends in different parts of the world. We do this through the means of probabilistic demographic projections.

Ageing, in most regions of the world, is caused mainly by changes in fertility and mortality rates, although in some regions migration also plays an important role. A powerful demographic regularity that we observe in many countries and in all regions of the world is the demographic transition (Notestein 1945; Kirk 1996). In the past, both fertility rates and mortality rates have been high. In most places, mortality rates begin to fall first, initiating a period of relatively rapid population growth. After a while, this mortality transition is followed by a fertility transition that brings fertility to a low level, usually below replacement. This pattern of demographic change is likely to run its course in all parts of the world well before the middle of the current century and will probably be replaced with dynamics that we can only dimly perceive today.

In terms of mortality, life expectancies in today's low mortality countries have been increasing at a fairly constant pace over the last 50 years (Oeppen and Vaupel 2002; Bongaarts 2006). Life expectancies in some countries and regions have been catching up with the leaders (United Nations 2007). In others, they have been falling behind. We expect that this pattern of catching up and falling behind is likely to continue. This is one of the reasons for the uncertainty in the speed of ageing.

In terms of fertility, the world today can be divided into three groups of countries, a few that have not yet fully entered the fertility transition, a group that are in the midst of their fertility transitions, and a group that are in their final (low fertility) phase. We expect that fertility transitions will continue to run their course, so that by mid-century it is likely that all regions of the world will be in the last phase of the transition. This provides another source of change in the drivers of ageing. There is still 
likely to be a great deal of variability in the specific timing as well as in the fertility in the final stage of the transition, but the phase of general fertility decline is likely to be over almost everywhere by mid-century. This variability adds to the long term uncertainty about the magnitude of ageing.

The ageing that we will see in most world regions in the early part of this century is driven by the forces of past life expectancy increases and catch-up and past reductions in fertility. In the longer-term, these forces will change and slowly these changes will be reflected in our measures of ageing.

Uncertainty is a fundamental part of any demographic forecast. In 1981, Nathan Keyfitz, one of the giants of 20th century demography wrote:

Demographers can no more be held responsible for inaccuracy in forecasting population 20 years ahead than geologists, meteorologists, or economists when they fail to announce earthquakes, cold winters, or depressions 20 years ahead. What we can be held responsible for is warning one another and our public what the error of our estimates is likely to be. (Keyfitz 1981: 579)

In this paper, we follow Keyfitz's invocation and provide new estimates of various measures of ageing along with assessments of their uncertainty. Section 2 of this paper presents the results of a new set of probabilistic world and regional population forecasts (Lutz et al. 2008). They confirm the finding that we presented earlier (Lutz et al. 2001a) that it is highly likely that the world's population growth will come to the end during the 21st century.

Section 3 presents our findings for the proportions of populations $60+$ and in Section 4 we show the results for conventional old age dependency ratios. Figures for proportions 80+ are presented in Section 5 and Section 6 discusses ageing as viewed from the perspective of average ages. In Section 7, we present a new measure of ageing that takes changes in life expectancy into account. Section 8 contains our concluding thoughts.

\section{New Regional and Global Probabilistic Population Forecasts}

Probabilistic population forecasts use random draws from distributions of total fertility rates, life expectancies at birth, and migration rates to produce distributions of population and age structure outcomes. The distributions of those figures come from information originally obtained from experts and updated according to the most recent observations (Lutz et al. 2001a, 2004, 2008). They utilize time series statistical techniques and have been evaluated to ensure that they are consistent with magnitudes to be expected from the ex post analysis of errors in past United Nations (UN) forecasts. The assumptions underlying the forecasts were originally set out in Lutz et al. (2001a) and justified in some detail in Lutz et al. (2004). They have been updated in Lutz et al. (2008). A brief statement of them appears in the Appendix. 
Our probabilistic forecasts begin with the age and gender structure of regional populations in 2000. ${ }^{1}$ The 13 regions are North Africa, Sub-Saharan Africa, North America, Latin America, Central Asia, Middle East, South Asia, China Region, Pacific Asia, Japan/Oceania, Western Europe, Eastern Europe, and the European portion of the former Soviet Union (FSU). A listing of the countries included in each region can be found in Lutz et al. (2004: 63-66). The first step in making a forecast for 2001 is to draw random total fertility rates, random life expectancies at birth, and random migration rates for each of our 13 regions. Fertility and mortality rates are assumed to be correlated across regions. Fertility and mortality rates are assumed not to be correlated with one another within regions, but current fertility rates and current mortality rates in each region are correlated with past values of their own series. Age-specific birth rates are assumed to follow standard patterns given the assumed level of total fertility rates. Similarly, age-specific survival rates are derived from the life expectancies at birth, and age-specific migration rates are derived from the random number of migrants. With these age-specific rates and the age structure in the initial year, we can forecast the population from the base year 2000 to the first projection year 2001. We repeat this process through 2100, keeping track of the contemporaneous interregional correlations and the correlations of fertility and mortality rates with their past values. This gives us one complete path of population and age structures. When we duplicate this process one thousand times, we obtain distributions of the demographic measures of interest.

Probabilistic population forecasts which consider the uncertainty in all three components of population change (fertility, mortality and migration) have a number of advantages over the presentation of a small set of variants, such as those provided by the United Nations Population Division (for example, United Nations 2008) especially when it comes to the study of ageing. The UN low, medium, and high variants differ only in terms of fertility. Because they do not reflect alternative mortality assumptions, the variants are not suitable for the study of the uncertainty in the patterns of ageing, where mortality variability is an important part of the explanation. In addition, the UN variants assume a perfect correlation in fertility rates across countries. In the UN low variant, for example, all countries in the world have relatively low fertility. If Germany has comparatively low fertility, so will Gabon. There is no possibility that low fertility in one region can ever be compensated by high fertility in another.

Figure 1 shows the time paths of world population size in nine of the thousand simulated futures that we have generated. They have been chosen so that each one has in 2100 a world population size corresponding to one of the deciles of the distribution of world population sizes in that year. It is clear from that Figure that world population sizes can go up and go down. Our simulated population paths allow there to be future baby booms and busts. They allow for the possibility of substantial increases in human life expectancy as well as the possibility of significant decreases in life expectancy, which could possibly be caused by environmental disasters or epidemics.

\footnotetext{
${ }^{1}$ For most regions, we used observed fertility, mortality, and migration data for the period 2000 to 2006. However, in the China Region, Sub-Saharan Africa, and South Asia fertility was uncertain even in 2000 (see Appendix).
} 


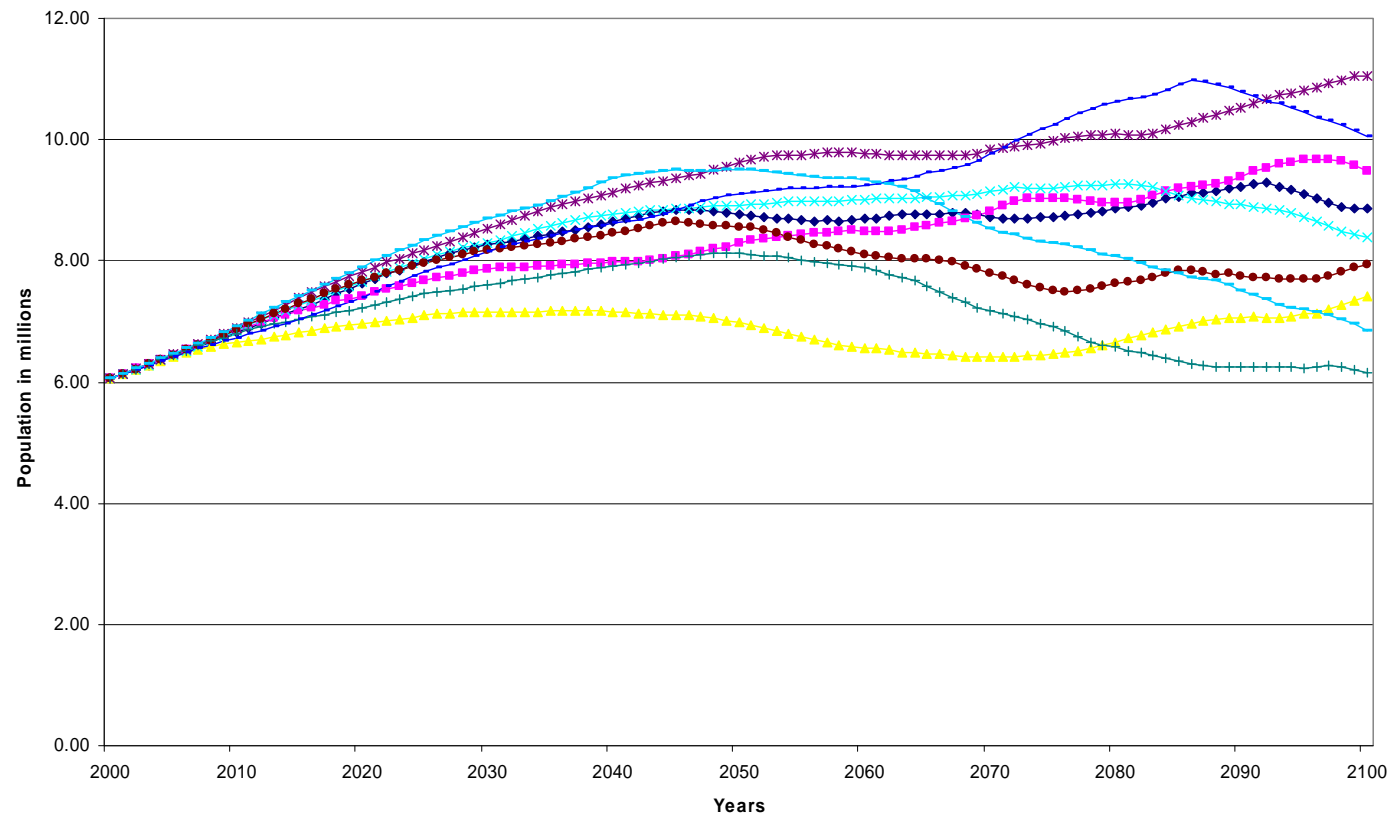

Figure 1. Nine simulated paths of world population. Note: These paths were chosen out of our 1,000 simulated futures so that each one ends at one of the deciles of the distribution of world population sizes in 2100.

Figure 2 shows the famous graph of global human population sizes from the year 1000 onward. For most of the span in that graph, the human population grew slowly. Around 1800, the population growth rate increased due to declining mortality and reached a peak in the 1950s. What is not so often seen is the feathered part of the graph on the right indicating the uncertainty of world population sizes in the current century. Clearly, it is likely that the world's population growth will come to an end during this century. The ending of world population growth has implications for ageing, which we will discuss in the following sections. The main reason that world population growth is likely to come to an end this century is that most countries of the world will eventually reach the final stage of the demographic transition where fertility will probability be below the replacement level. Eventually, below replacement fertility will result in falling populations in most regions of the world by the end of the century, once population momentum is exhausted. 


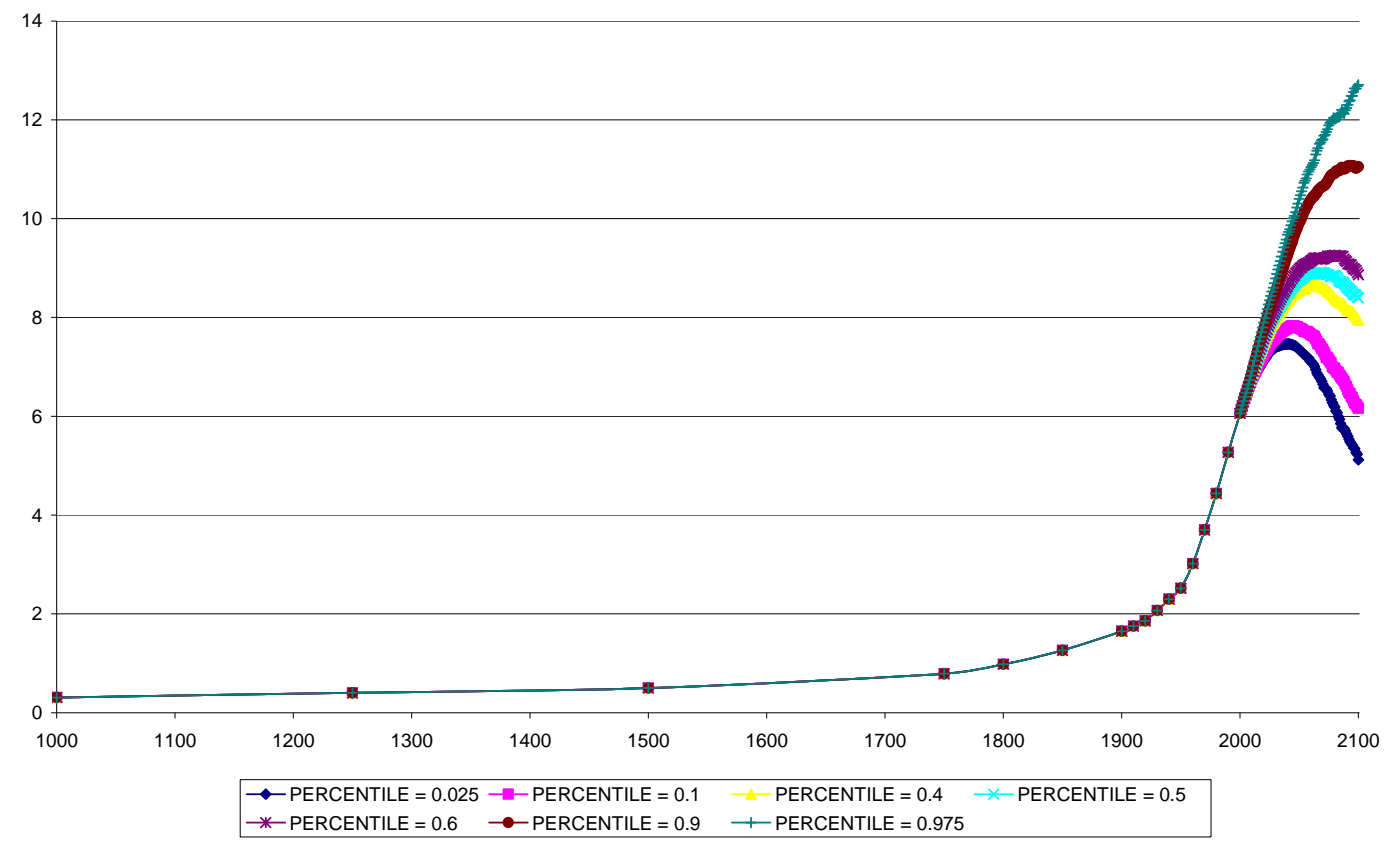

Figure 2. Estimated world population size from 1000 to 2000. Distribution of forecasted world population sizes 2001 to 2100. Source: Estimates for the years 1000 to 2000 from United Nations (1999).

In Figure 3, we show the probability that a peak will be reached in global and regional populations by year from 2000 to 2100. Eastern Europe and the European part of the Former Soviet Union are already on a declining trajectory and have with great probability already surpassed its peak. The curve for Japan/Oceania rises quickly and shows that by 2010 there is over a 40 percent chance that the peak population of that region will already be reached. By 2025 that probability rises to almost 70 percent. The China Region initially has a lower probability of peaking, but that probability rises over time, so it also becomes almost 70 percent in 2025. There is a 90 percent chance that the population of the China Region will have reached its peak some time before 2040.

At the other extreme, the chance that Sub-Saharan Africa will have reached its population peak by 2050 is virtually zero. That probability rises slowly at first after 2050, but then with increasing speed, so that by 2100 it increases to around 64 percent. This figure is marginally lower than that for Latin America, where the probability of peaking increases almost linearly from 2060 onward. 


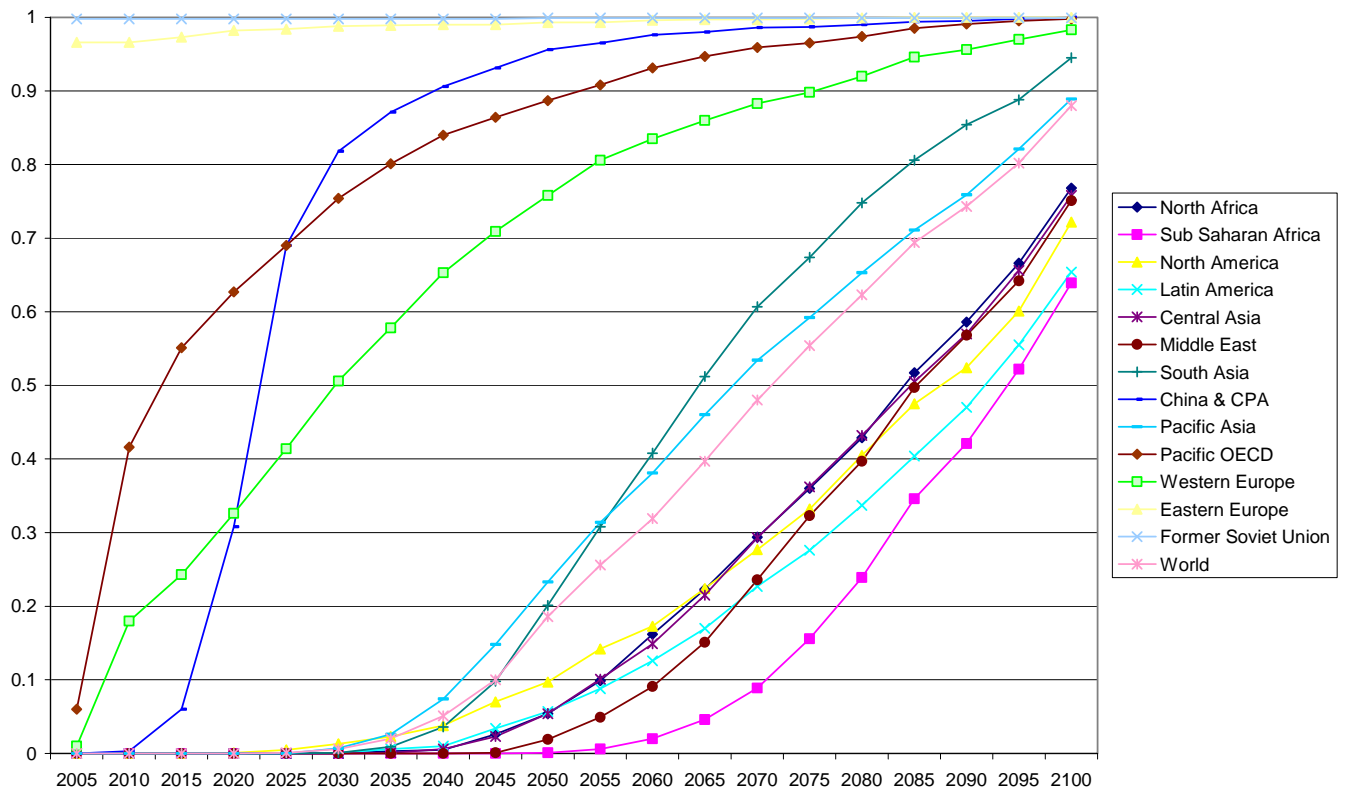

Figure 3. Probability that global and regional populations will reach a peak by the indicated date.

Over the course of this century, demographic conditions will become ever more polarized. Figure 4a shows the forecasted distribution of the population of Sub-Saharan Africa and Figure 4b shows it for Eastern Europe. According to the mean outcomes, we expect that the population of Sub-Saharan Africa will more than triple in this century, while the population of Eastern Europe is anticipated to fall by over one-half. These enormous differences in rates of population growth will also be reflected in the patterns of population ageing. 


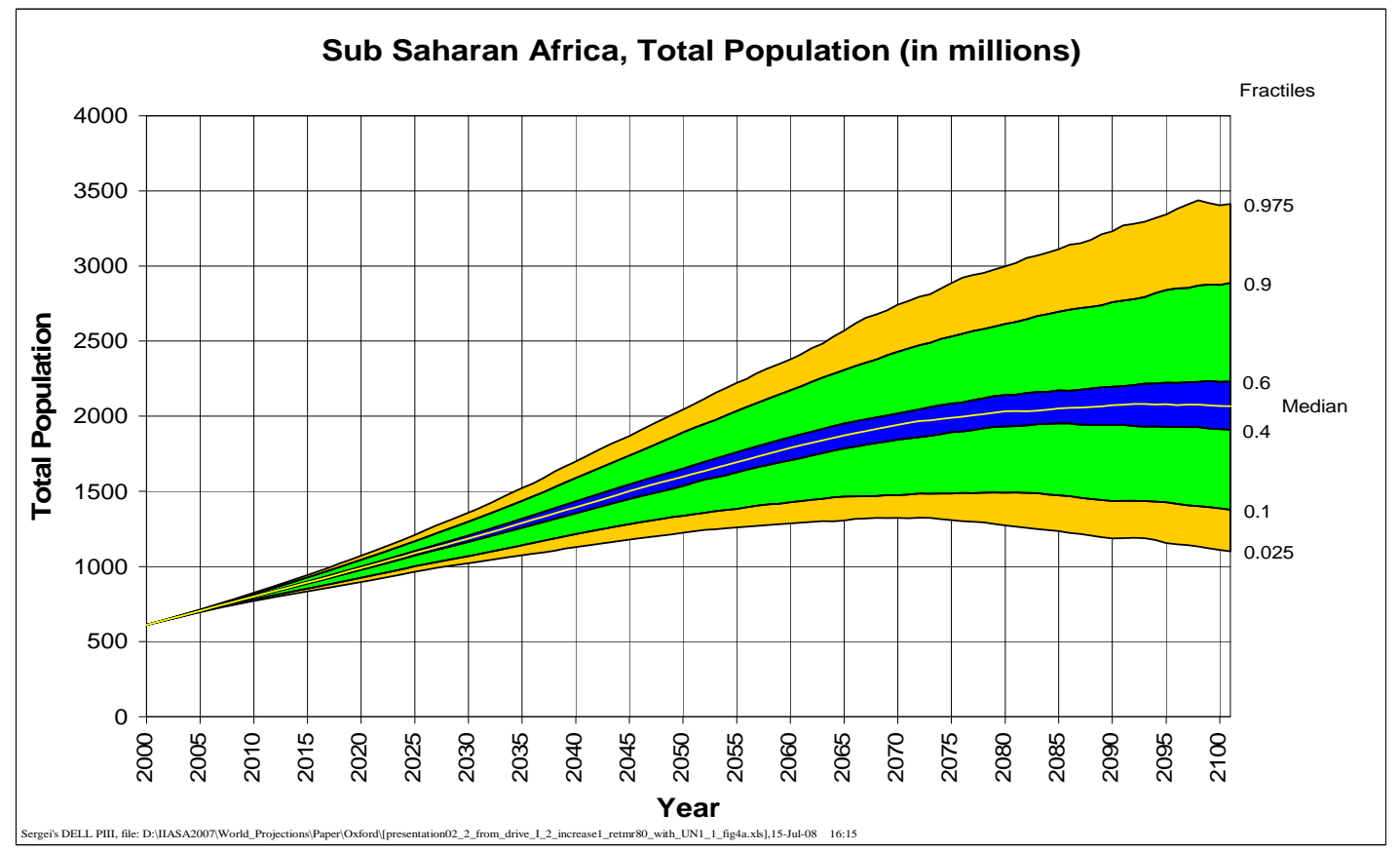

Figure 4a. Distribution of forecasted populations of Sub-Saharan Africa, 2000 to 2100.

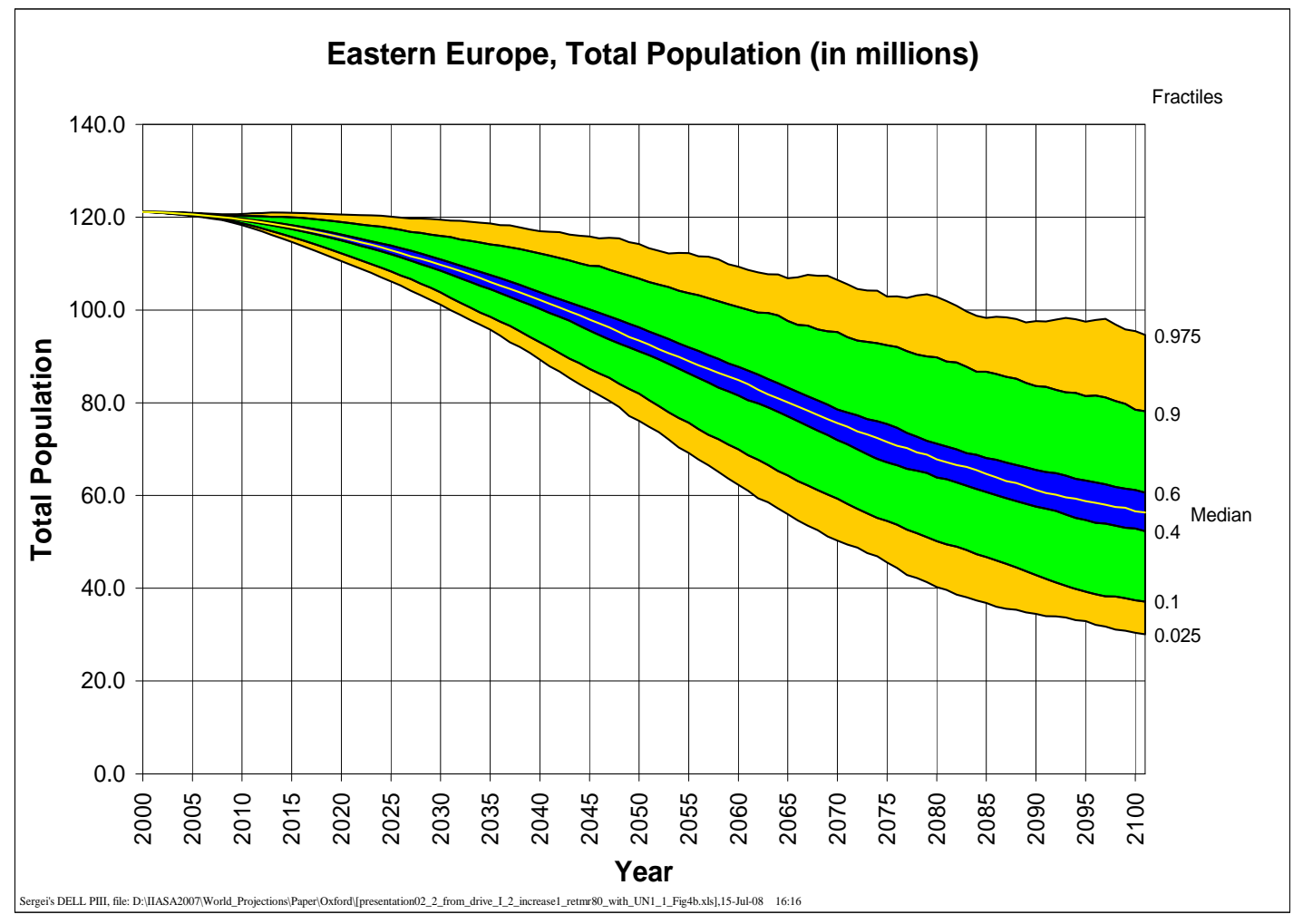

Figure 4b. Distribution of forecasted populations of Eastern Europe, 2000 to 2100. 
Table 1 shows the mean population sizes and 80 percent confidence intervals for the world and 13 major regions based on our 1,000 simulated population futures. We present the results for 2000 (based on observations), 2010, 2025, 2050, 2075, and 2100. All the detailed data underlying this and other Tables and Figures in the paper are available from the authors upon request.

World population was around 6.1 billion people in 2000. Using the mean forecast, we anticipate it to rise to around 7.8 billion in 2025. After that we expect the world's population to rise by around 1 billion people to 2050 and then by another billion by 2075 . This would be the last billion people to be added to the world's population. By 2100, our mean forecasts show a world with about 400 million fewer people than it had a quarter of a century earlier. Of course, we do not think that the path of world's population is likely to follow the means of our distributions. It is quite possible that the last billion people will be added earlier or later.

In 2000, the China Region had the largest population size among all the regions in the Table with around 1.41 billion people. The mean of our forecast for the China Region falls to 1.34 billion in 2050 and then plummets to 0.85 billion in 2100 . The next largest region in the Table in 2000 is South Asia with a population of 1.37 billion. The mean forecast for it in 2050 is 1.61 billion, making it the region with the largest population at that time. The population there is expected to continue to grow in the second half of the century, reaching a mean forecasted value of 2.12 billion. However, neither the China Region nor South Asia is expected to have the largest population in 2100 according to the average of our forecasts. That distinction falls to Sub-Saharan Africa, which started the century with a population of 0.61 billion. The mean forecast for that region rises stunningly to 1.61 billion in 2050 and then to 2.12 billion in 2100 . According to the mean forecast, around half of the population of the world in 2100 will be living either in Sub-Saharan Africa or South Asia. Of course, as indicated by our 80 percent confidence intervals, there is substantial uncertainty associated with all of these forecasts. 
Table 1. Probabilistic forecasts of global and regional population sizes. The main figures in the Table are means of 1,000 simulated futures. The figures in parentheses are 80 percent prediction intervals. Population sizes are in millions, except for South Asia, China Region, and the World, where they are in billions.

\begin{tabular}{|c|c|c|c|c|c|c|}
\hline & 2000 & 2010 & 2025 & 2050 & 2075 & 2100 \\
\hline \multirow[t]{2}{*}{ North Africa } & 173.3 & 207.6 & 253.5 & 305.8 & 328.3 & 330.5 \\
\hline & (173.3-173.3) & $(205.3-210.1)$ & (238.1-268.2) & $(267.3-346.2)$ & (261.1-399.7) & (236.4-432.9) \\
\hline \multirow[t]{2}{*}{ Sub-Saharan Africa } & 611.2 & 799.0 & 1086.2 & 1608.2 & 2011.7 & 2119.2 \\
\hline & (611.2-611.2) & (781.3-815.5) & $(1000.6-1168.2)$ & (1337.2-1892.7) & (1485.5-2531.3) & (1386.1-2874.3) \\
\hline \multirow[t]{3}{*}{ North America } & 313.7 & 338.5 & 380.2 & 426.6 & 449.3 & 464.5 \\
\hline & $(313.7-313.7)$ & $(332-345)$ & (358.8-402.3) & (372.8-484) & (362.2-538.5) & (336.8-598.5) \\
\hline & 0.000 & 0.015 & 0.045 & 0.100 & 0.156 & 0.214 \\
\hline \multirow[t]{2}{*}{ Latin America } & 515.3 & 595.3 & 703.4 & 833.0 & 903.2 & 947.5 \\
\hline & (515.3-515.3) & (589.9-600.8) & (669.2-738.9) & (734.3-933.2) & (719.7-1094.9) & (672.7-1228.5) \\
\hline \multirow[t]{2}{*}{ Central Asia } & 55.9 & 65.3 & 79.2 & 95.8 & 102.9 & 102.9 \\
\hline & (55.9-55.9) & $(64.7-65.8)$ & (75.1-83.5) & $(84-107.6)$ & (81.6-124.8) & $(72.3-133.1)$ \\
\hline \multirow[t]{3}{*}{ Middle East } & 172.1 & 214.4 & 277.4 & 357.0 & 394.5 & 396.4 \\
\hline & $(172.1-172.1)$ & $(212.2-216.7)$ & (260.8-294.6) & (314.4-402.2) & (314.6-473.8) & (291.2-509.7) \\
\hline & 0.000 & 0.008 & 0.048 & 0.096 & 0.158 & 0.221 \\
\hline \multirow[t]{2}{*}{ South Asia } & 1.367 & 1.625 & 1.957 & 2.285 & 2.290 & 2.041 \\
\hline & $(1.367-1.367)$ & $(1.601-1.651)$ & (1.837-2.078) & (1.983-2.603) & $(1.77-2.832)$ & $(1.385-2.709)$ \\
\hline \multirow[t]{2}{*}{ China Region } & 1.408 & 1.467 & 1.506 & 1.342 & 1.064 & 0.853 \\
\hline & $(1.408-1.408)$ & $(1.445-1.489)$ & $(1.442-1.566)$ & $(1.177-1.519)$ & $(0.81-1.332)$ & $(0.575-1.182)$ \\
\hline \multirow[t]{2}{*}{ Pacific Asia } & 476.4 & 541.7 & 622.6 & 699.2 & 699.9 & 657.8 \\
\hline & $(476.4-476.4)$ & $(537.3-546)$ & (593.9-651.7) & (619.5-786.7) & (562.1-841.4) & $(477.8-869.4)$ \\
\hline \multirow[t]{2}{*}{ Japan/Oceania } & 149.9 & 151.5 & 149.2 & 136.0 & 115.6 & 99.2 \\
\hline & (149.9-149.9) & $(150.3-152.9)$ & (142.6-155.8) & (118.3-154.6) & (88.9-143.8) & $(68.3-130.2)$ \\
\hline \multirow[t]{2}{*}{ Western Europe } & 455.6 & 462.2 & 467.4 & 447.6 & 395.7 & 353.4 \\
\hline & (455.6-455.6) & (458.3-466) & (448-487.6) & (391.9-507.9) & (311.3-489.3) & $(246.9-462.2)$ \\
\hline \multirow[t]{2}{*}{ Eastern Europe } & 121.2 & 119.5 & 112.9 & 93.9 & 72.3 & 57.9 \\
\hline & $(121.2-121.2)$ & $(118.7-120.3)$ & (108.3-117.6) & (81.9-106.7) & $(54.5-92.4)$ & (37.4-78.5) \\
\hline \multirow[t]{2}{*}{ European FSU } & 235.6 & 227.6 & 210.0 & 169.3 & 130.2 & 109.1 \\
\hline & $(235.6-235.6)$ & (226.1-228.9) & (201.6-218.2) & $(146.6-192)$ & (96.9-165.8) & (68.1-149.5) \\
\hline \multirow[t]{2}{*}{ World } & 6.055 & 6.815 & 7.805 & 8.800 & 8.958 & 8.533 \\
\hline & (6.055-6.055) & (6.745-6.883) & $(7.442-8.164)$ & $(7.783-9.903)$ & $(7.146-10.799)$ & (6.161-11.05) \\
\hline
\end{tabular}




\section{Proportions of the Population 60+ Years Old}

Table 2 shows the data for proportions of the population who are 60 years old or older. It shows that increases in this measure will almost certainly be observed in every region of the world between 2000 and 2050. The lower bounds of the 80 percent confidence intervals in 2050 are well above the levels of the corresponding proportions in 2000. Sub-Saharan Africa stands out as being a bit different from the other regions in this regard. In that region 4.6 percent of the population was $60+$ in 2000. In 2050, the lower bound of the 80 percent confidence interval is 5.5 percent. This is still above 4.6 percent, but it suggests that there is a small possibility that very little ageing would occur there.

The Japan/Oceania region leads the world in the proportion of 60+ year olds. In 2000, 22.0 percent of that region's population was that old. The mean of our forecasts for 2025 is 33.0 percent. It is 42.4 percent in 2050 and over one half by the end of the century. It is quite striking that we expect a region to have a majority of its population over age 60 by 2100. Japan is older than Australia and New Zealand, the other two countries in that region. Therefore, in Japan we would expect that proportion to be even higher. This may lead not only to socio-economics consequences, but to political ones as well (Sanderson and Scherbov 2007).

The uncertainties associated with forecasts of the year 2100 are, naturally, very large. In the case of the Japan/Oceania region the 80 percent confidence interval in 2100 ranges from 37.4 percent to 62.3 percent. Since the mean forecast for 2050 was 42.4 percent, there is a possibility that the Japan/Oceania region would experience little or no increase in the proportion 60+ during the last half of the century. On the other hand, there is a ten percent chance that the proportion of the 60+ year old population will exceed 62.3 percent.

In most regions of the world, we see a slower increase in the proportion of the $60+$ population in the second half of the century than the first. A striking example of this is the European portion of the former Soviet Union. There, the proportion of the $60+$ population increases from 18.7 percent in 2000 to an average forecast of 40.1 percent in 2050. This indicates quite rapid ageing. After 2050, however, the story is quite different. The mean forecasted proportion 60+ rises marginally to 41.2 percent in 2070, and then falls to 39.1 percent in 2100. This phenomenon is due to two factors. The first is the very low fertility in that region in the recent past and its likely continuation in the near-term future. The second is our assumption that on average fertility levels will increase in this region to a level of some Western European countries today. There is quite a bit of uncertainty in these numbers, but they do suggest that the experience of population ageing will be substantially different before and after midcentury. A similar pattern in the speed of population ageing can be seen in Eastern Europe.

The Middle East is a region where we see rapid increases in the proportion 60+ happening throughout the century. Only 5.6 percent of the people there were $60+$ years old in 2000. The mean of our forecasts increases to 18.6 percent in 2050 and then continues around the same pace of increase, reaching 34.6 percent in 2100 . This is only 4.2 percentage points lower than the figure for North America at that date. The six-fold increase in the proportion of the people in the population who are 60+ years old during the century is one of the most striking examples of ageing that we see in Table 2. 
Table 2. Probabilistic forecasts of global and regional proportions of populations 60+ years old. The main figures in the Table are means of 1,000 simulated futures. The figures in parentheses are 80 percent prediction intervals.

\begin{tabular}{|c|c|c|c|c|c|c|}
\hline & 2000 & 2010 & 2025 & 2050 & 2075 & 2100 \\
\hline North Africa & $\begin{array}{c}0.061 \\
(0.061-0.061)\end{array}$ & $\begin{array}{c}0.068 \\
(0.067-0.069)\end{array}$ & $\begin{array}{c}0.104 \\
(0.096-0.111)\end{array}$ & $\begin{array}{c}0.193 \\
(0.164-0.224)\end{array}$ & $\begin{array}{c}0.274 \\
(0.217-0.339)\end{array}$ & $\begin{array}{c}0.320 \\
(0.241-0.416)\end{array}$ \\
\hline Sub-Saharan Africa & $\begin{array}{c}0.046 \\
(0.046-0.046)\end{array}$ & $\begin{array}{c}0.044 \\
(0.043-0.045)\end{array}$ & $\begin{array}{c}0.048 \\
(0.044-0.051)\end{array}$ & $\begin{array}{c}0.066 \\
(0.055-0.078)\end{array}$ & $\begin{array}{c}0.134 \\
(0.105-0.166)\end{array}$ & $\begin{array}{c}0.202 \\
(0.16-0.253)\end{array}$ \\
\hline North America & $\begin{array}{c}0.164 \\
(0.164-0.164)\end{array}$ & $\begin{array}{c}0.181 \\
(0.178-0.184)\end{array}$ & $\begin{array}{c}0.254 \\
(0.236-0.272)\end{array}$ & $\begin{array}{c}0.294 \\
(0.239-0.346)\end{array}$ & $\begin{array}{c}0.346 \\
(0.264-0.424)\end{array}$ & $\begin{array}{c}0.388 \\
(0.284-0.487)\end{array}$ \\
\hline Latin America & $\begin{array}{c}0.079 \\
(0.079-0.079)\end{array}$ & $\begin{array}{c}0.089 \\
(0.088-0.09)\end{array}$ & $\begin{array}{c}0.132 \\
(0.124-0.141)\end{array}$ & $\begin{array}{c}0.223 \\
(0.187-0.264)\end{array}$ & $\begin{array}{c}0.283 \\
(0.218-0.354)\end{array}$ & $\begin{array}{c}0.323 \\
(0.231-0.42)\end{array}$ \\
\hline Central Asia & $\begin{array}{c}0.083 \\
(0.083-0.083)\end{array}$ & $\begin{array}{c}0.076 \\
(0.076-0.077)\end{array}$ & $\begin{array}{c}0.120 \\
(0.112-0.128)\end{array}$ & $\begin{array}{c}0.204 \\
(0.171-0.238)\end{array}$ & $\begin{array}{c}0.279 \\
(0.215-0.349)\end{array}$ & $\begin{array}{c}0.335 \\
(0.247-0.43)\end{array}$ \\
\hline Middle East & $\begin{array}{c}0.056 \\
(0.056-0.056)\end{array}$ & $\begin{array}{c}0.060 \\
(0.059-0.06)\end{array}$ & $\begin{array}{c}0.090 \\
(0.083-0.097)\end{array}$ & $\begin{array}{c}0.186 \\
(0.156-0.219)\end{array}$ & $\begin{array}{c}0.285 \\
(0.222-0.351)\end{array}$ & $\begin{array}{c}0.346 \\
(0.253-0.437)\end{array}$ \\
\hline South Asia & $\begin{array}{c}0.070 \\
(0.07-0.07)\end{array}$ & $\begin{array}{c}0.076 \\
(0.075-0.077)\end{array}$ & $\begin{array}{c}0.104 \\
(0.096-0.111)\end{array}$ & $\begin{array}{c}0.176 \\
(0.148-0.206)\end{array}$ & $\begin{array}{c}0.271 \\
(0.216-0.334)\end{array}$ & $\begin{array}{c}0.352 \\
(0.268-0.443)\end{array}$ \\
\hline China Region & $\begin{array}{c}0.099 \\
(0.099-0.099)\end{array}$ & $\begin{array}{c}0.121 \\
(0.119-0.123)\end{array}$ & $\begin{array}{c}0.200 \\
(0.189-0.212)\end{array}$ & $\begin{array}{c}0.356 \\
(0.303-0.414)\end{array}$ & $\begin{array}{c}0.416 \\
(0.316-0.519)\end{array}$ & $\begin{array}{c}0.427 \\
(0.308-0.554)\end{array}$ \\
\hline Pacific Asia & $\begin{array}{c}0.076 \\
(0.076-0.076)\end{array}$ & $\begin{array}{c}0.089 \\
(0.088-0.09)\end{array}$ & $\begin{array}{c}0.137 \\
(0.129-0.145)\end{array}$ & $\begin{array}{c}0.230 \\
(0.194-0.266)\end{array}$ & $\begin{array}{c}0.291 \\
(0.227-0.36)\end{array}$ & $\begin{array}{c}0.358 \\
(0.266-0.456)\end{array}$ \\
\hline Japan/Oceania & $\begin{array}{c}0.220 \\
(0.22-0.22)\end{array}$ & $\begin{array}{c}0.275 \\
(0.272-0.277)\end{array}$ & $\begin{array}{c}0.330 \\
(0.308-0.351)\end{array}$ & $\begin{array}{c}0.424 \\
(0.358-0.489)\end{array}$ & $\begin{array}{c}0.464 \\
(0.36-0.568)\end{array}$ & $\begin{array}{c}0.505 \\
(0.374-0.623)\end{array}$ \\
\hline Western Europe & $\begin{array}{c}0.199 \\
(0.199-0.199)\end{array}$ & $\begin{array}{c}0.214 \\
(0.212-0.216)\end{array}$ & $\begin{array}{c}0.279 \\
(0.261-0.297)\end{array}$ & $\begin{array}{c}0.372 \\
(0.314-0.435)\end{array}$ & $\begin{array}{c}0.416 \\
(0.316-0.512)\end{array}$ & $\begin{array}{c}0.455 \\
(0.337-0.572)\end{array}$ \\
\hline Eastern Europe & $\begin{array}{c}0.177 \\
(0.177-0.177) \\
0.000\end{array}$ & $\begin{array}{c}0.200 \\
(0.199-0.202) \\
0.006\end{array}$ & $\begin{array}{c}0.272 \\
(0.256-0.289) \\
0.046\end{array}$ & $\begin{array}{c}0.416 \\
(0.357-0.477) \\
0.113\end{array}$ & $\begin{array}{c}0.447 \\
(0.339-0.56) \\
0.194\end{array}$ & $\begin{array}{c}0.447 \\
(0.32-0.58) \\
0.220\end{array}$ \\
\hline European FSU & $\begin{array}{c}0.187 \\
(0.187-0.187)\end{array}$ & $\begin{array}{c}0.190 \\
(0.189-0.191)\end{array}$ & $\begin{array}{c}0.272 \\
(0.258-0.286)\end{array}$ & $\begin{array}{c}0.401 \\
(0.343-0.458)\end{array}$ & $\begin{array}{c}0.412 \\
(0.308-0.517)\end{array}$ & $\begin{array}{c}0.391 \\
(0.282-0.513)\end{array}$ \\
\hline World & $\begin{array}{c}0.100 \\
(0.1-0.1)\end{array}$ & $\begin{array}{c}0.108 \\
(0.107-0.109)\end{array}$ & $\begin{array}{c}0.149 \\
(0.14-0.157)\end{array}$ & $\begin{array}{c}0.220 \\
(0.188-0.256)\end{array}$ & $\begin{array}{c}0.277 \\
(0.218-0.34)\end{array}$ & $\begin{array}{c}0.327 \\
(0.251-0.409)\end{array}$ \\
\hline
\end{tabular}


Figure 5 shows the fraction of our 1,000 simulated futures in which the proportion of the population 60+ years old exceeds one-third for selected regions. There are a number of distinct clusters in the Figure. To the left are the regions where high proportions $60+$ come early. This cluster is bounded by the Japan/Oceania region where the one-third level is reached earliest in the China Region. Another cluster of regions where the one-third level will come considerably later in the century include Pacific Asia, Latin America, and South Asia (not all shown in the graph). In between, North America stands out as having a unique temporal path of ageing. Sub-Saharan Africa (not shown in the graph) also stands out as being unique. The proportion of paths on which the fraction of $60+$ year olds exceeds one-third barely rises above zero by the end of the century.

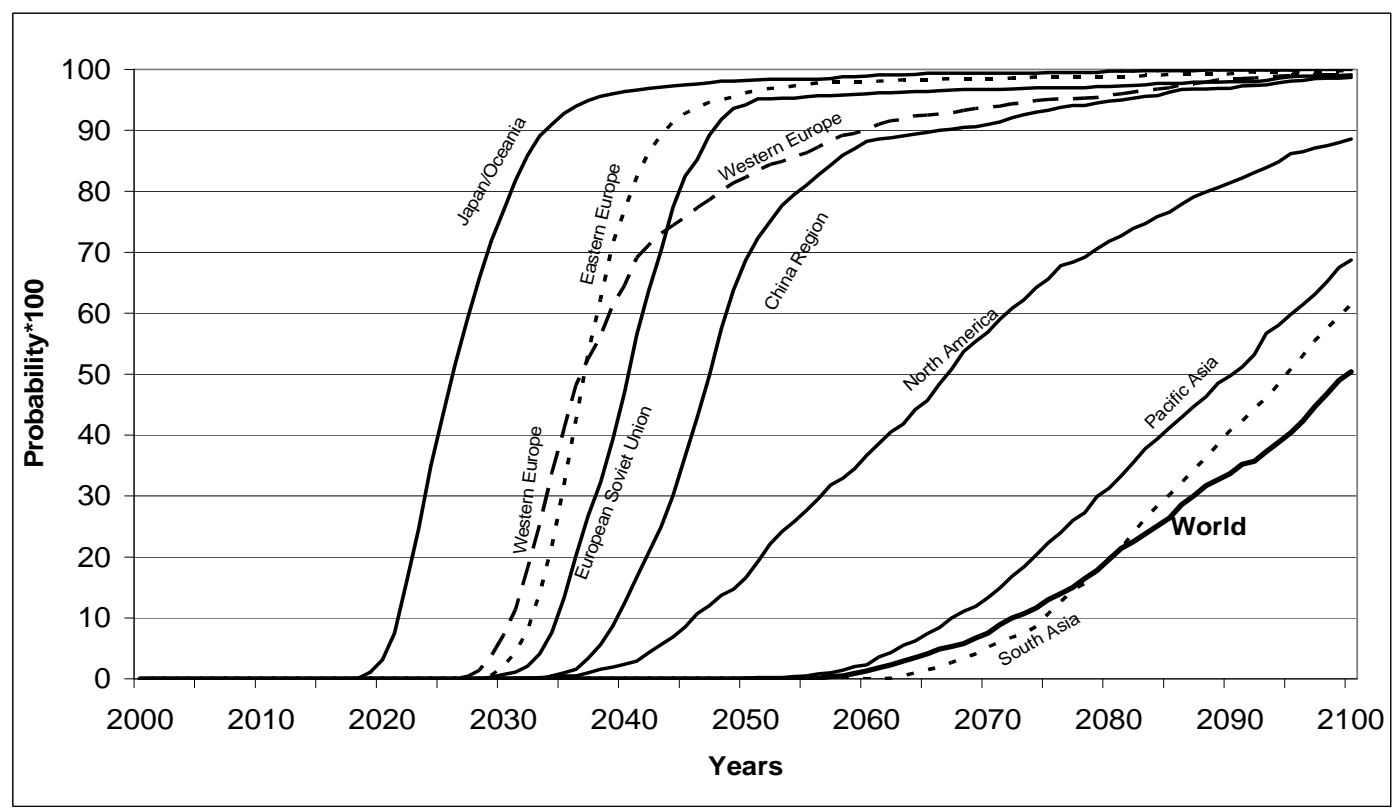

Figure 5. Percent of 1,000 simulated futures in which the proportion of the population $60+$ exceeds one-third by the indicated date.

\section{Old Age Dependency Ratios}

The old age dependency ratio (OADR) here is defined as the ratio of the population 60+ years old to the population 20 to 59 years old. This ratio was named many years ago, but now the word "dependency" has become quite anachronistic. Many 60+ year olds should not be considered dependent. Nevertheless, the ratio provides us with an interesting measure of age structure that can be used in studies of population ageing.

Again we see from Table 3 that the Japan/Oceania region is the oldest. The OADR was 0.392 in 2000. By 2010, it will rise by over 0.12 to 0.518 . In 2010, for every 100 Japanese in the age group 20 to 59, we would expect there to be nearly 52 Japanese $60+$. The rapid rise in the OADR continues after that. By 2050, for every 100 Japanese 20 to 59 years old, we expect there to be around 101 who are $60+$. By 2100, the average forecast is that there would be around 151 Japanese 60+ for every 100 who are 20 to 59 . 
Table 3. Probabilistic forecasts of global and regional Old Age Dependency Ratios (population 60+/population 20 to 59). The main figures in the Table are means of 1,000 simulated futures. The figures in parentheses are 80 percent prediction intervals.

\begin{tabular}{|c|c|c|c|c|c|c|}
\hline & 2000 & 2010 & 2025 & 2050 & 2075 & 2100 \\
\hline North Africa & $\begin{array}{c}0.130 \\
(0.13-0.13)\end{array}$ & $\begin{array}{c}0.132 \\
(0.132-0.133)\end{array}$ & $\begin{array}{c}0.192 \\
(0.184-0.201)\end{array}$ & $\begin{array}{c}0.362 \\
(0.302-0.425)\end{array}$ & $\begin{array}{c}0.566 \\
(0.414-0.745)\end{array}$ & $\begin{array}{c}0.708 \\
(0.457-1.021)\end{array}$ \\
\hline Sub-Saharan Africa & $\begin{array}{c}0.116 \\
(0.116-0.116)\end{array}$ & $\begin{array}{c}0.112 \\
(0.112-0.113)\end{array}$ & $\begin{array}{c}0.111 \\
(0.109-0.112)\end{array}$ & $\begin{array}{c}0.127 \\
(0.112-0.144)\end{array}$ & $\begin{array}{c}0.249 \\
(0.196-0.309)\end{array}$ & $\begin{array}{c}0.376 \\
(0.285-0.487)\end{array}$ \\
\hline North America & $\begin{array}{c}0.297 \\
(0.297-0.297)\end{array}$ & $\begin{array}{c}0.327 \\
(0.321-0.333)\end{array}$ & $\begin{array}{c}0.505 \\
(0.464-0.549)\end{array}$ & $\begin{array}{c}0.615 \\
(0.471-0.764)\end{array}$ & $\begin{array}{c}0.796 \\
(0.531-1.066)\end{array}$ & $\begin{array}{c}0.980 \\
(0.586-1.381)\end{array}$ \\
\hline Latin America & $\begin{array}{c}0.156 \\
(0.156-0.156)\end{array}$ & $\begin{array}{c}0.166 \\
(0.165-0.167)\end{array}$ & $\begin{array}{c}0.243 \\
(0.231-0.256)\end{array}$ & $\begin{array}{c}0.438 \\
(0.355-0.532)\end{array}$ & $\begin{array}{c}0.604 \\
(0.423-0.812)\end{array}$ & $\begin{array}{c}0.733 \\
(0.451-1.067)\end{array}$ \\
\hline Central Asia & $\begin{array}{c}0.178 \\
(0.178-0.178)\end{array}$ & $\begin{array}{c}0.144 \\
(0.144-0.145)\end{array}$ & $\begin{array}{c}0.224 \\
(0.214-0.234)\end{array}$ & $\begin{array}{c}0.388 \\
(0.32-0.462)\end{array}$ & $\begin{array}{c}0.576 \\
(0.409-0.772)\end{array}$ & $\begin{array}{c}0.746 \\
(0.473-1.072)\end{array}$ \\
\hline Middle East & $\begin{array}{c}0.126 \\
(0.127-0.127)\end{array}$ & $\begin{array}{c}0.120 \\
(0.12-0.121)\end{array}$ & $\begin{array}{c}0.169 \\
(0.161-0.178)\end{array}$ & $\begin{array}{c}0.347 \\
(0.287-0.413)\end{array}$ & $\begin{array}{c}0.591 \\
(0.417-0.785)\end{array}$ & $\begin{array}{c}0.783 \\
(0.494-1.107)\end{array}$ \\
\hline South Asia & $\begin{array}{c}0.146 \\
(0.146-0.146)\end{array}$ & $\begin{array}{c}0.150 \\
(0.15-0.151)\end{array}$ & $\begin{array}{c}0.192 \\
(0.185-0.2)\end{array}$ & $\begin{array}{c}0.317 \\
(0.263-0.376)\end{array}$ & $\begin{array}{c}0.526 \\
(0.389-0.689)\end{array}$ & $\begin{array}{c}0.755 \\
(0.498-1.068)\end{array}$ \\
\hline China Region & $\begin{array}{c}0.175 \\
(0.175-0.175)\end{array}$ & $\begin{array}{c}0.196 \\
(0.195-0.197)\end{array}$ & $\begin{array}{c}0.337 \\
(0.32-0.356)\end{array}$ & $\begin{array}{c}0.741 \\
(0.588-0.915)\end{array}$ & $\begin{array}{c}1.016 \\
(0.633-1.445)\end{array}$ & $\begin{array}{c}1.114 \\
(0.624-1.708)\end{array}$ \\
\hline Pacific Asia & $\begin{array}{c}0.144 \\
(0.144-0.144)\end{array}$ & $\begin{array}{c}0.160 \\
(0.159-0.161)\end{array}$ & $\begin{array}{c}0.246 \\
(0.235-0.259)\end{array}$ & $\begin{array}{c}0.445 \\
(0.367-0.531)\end{array}$ & $\begin{array}{c}0.596 \\
(0.423-0.794)\end{array}$ & $\begin{array}{c}0.799 \\
(0.5-1.166)\end{array}$ \\
\hline Japan/Oceania & $\begin{array}{c}0.392 \\
(0.392-0.392)\end{array}$ & $\begin{array}{c}0.518 \\
(0.513-0.524)\end{array}$ & $\begin{array}{c}0.656 \\
(0.601-0.712)\end{array}$ & $\begin{array}{c}1.013 \\
(0.776-1.268)\end{array}$ & $\begin{array}{c}1.246 \\
(0.785-1.786)\end{array}$ & $\begin{array}{c}1.511 \\
(0.836-2.285)\end{array}$ \\
\hline Western Europe & $\begin{array}{c}0.360 \\
(0.36-0.36)\end{array}$ & $\begin{array}{c}0.384 \\
(0.38-0.387)\end{array}$ & $\begin{array}{c}0.530 \\
(0.492-0.57)\end{array}$ & $\begin{array}{c}0.826 \\
(0.636-1.046)\end{array}$ & $\begin{array}{c}1.031 \\
(0.651-1.449)\end{array}$ & $\begin{array}{c}1.245 \\
(0.723-1.854)\end{array}$ \\
\hline Eastern Europe & $\begin{array}{c}0.316 \\
(0.316-0.316)\end{array}$ & $\begin{array}{c}0.340 \\
(0.338-0.343)\end{array}$ & $\begin{array}{c}0.494 \\
(0.464-0.527)\end{array}$ & $\begin{array}{c}0.967 \\
(0.761-1.193)\end{array}$ & $\begin{array}{c}1.173 \\
(0.706-1.73)\end{array}$ & $\begin{array}{c}1.214 \\
(0.675-1.887)\end{array}$ \\
\hline European FSU & $\begin{array}{c}0.342 \\
(0.342-0.342)\end{array}$ & $\begin{array}{c}0.314 \\
(0.312-0.316)\end{array}$ & $\begin{array}{c}0.494 \\
(0.47-0.522)\end{array}$ & $\begin{array}{c}0.913 \\
(0.73-1.112)\end{array}$ & $\begin{array}{c}1.032 \\
(0.637-1.47)\end{array}$ & $\begin{array}{c}0.986 \\
(0.57-1.528)\end{array}$ \\
\hline World & $\begin{array}{c}0.196 \\
(0.196-0.196)\end{array}$ & $\begin{array}{c}0.203 \\
(0.202-0.204) \\
\end{array}$ & $\begin{array}{c}0.278 \\
(0.266-0.293) \\
\end{array}$ & $\begin{array}{c}0.428 \\
(0.356-0.506)\end{array}$ & $\begin{array}{c}0.570 \\
(0.414-0.743) \\
\end{array}$ & $\begin{array}{c}0.710 \\
(0.482-0.985) \\
\end{array}$ \\
\hline
\end{tabular}


The uncertainty associated with the figures in 2100 is, as usual, quite large. The 80 percent confidence interval spans the range from 0.836 to 2.285. The 0.836 figure is well below the average forecast for 2050 . The 2.285 is remarkably high - around 228 people $60+$ for each 100 who were 20 to 59 . Rapid ageing is clearly indicated for the Japan/Oceania region from 2000 to 2050. Even taking account of the uncertainties in our computations there can be little doubt about this. The period after 2050 is murkier. It is likely that the OADR will increase, but that is no longer certain.

The China Region is also ageing quite rapidly. The OADR there was 0.175 in 2000 and is expected to rise only modestly to 0.196 in 2010. Between 2010 and 2050, the average forecast shows a jump to 0.741 . The 80 percent confidence interval is between 0.588 and 0.915 , so we are confident that the figure in 2050 will be significantly above the one in 2010. The OADR in the China Region in 2050 is confidently expected to be higher than the OADR in any world region in Table 3 today. The OADR in the China Region is expected to continue to rise rapidly to 2100. Again, however, the uncertainty dilutes what we can confidently predict. The average OADR forecast for the China Region in 2100 is 111 people 60+ for each 100 people 20 to 59 . The 80 percent confidence interval around that figure is large, from 62 people to 171 people $60+$ per 100 people 20 to 59. It is possible therefore that the OADR does not increase between 2050 and 2100 or that it skyrockets.

In many other regions of the world, we are reasonably confident that the OADR will continue to increase throughout the century. Central Asia is one such place. Its OADR was 0.178 in 2000 and was expected to fall to 0.144 in 2010. After that it starts to increase rapidly to 0.388 in 2050 and then to 0.746 in 2100 . The 80 percent confidence interval in 2050 is between 0.320 and 0.462 . The 80 percent confidence interval in 2100 is 0.473 to 1.072 . Despite the large uncertainty around our forecast for 2100, it is still extremely unlikely that Central Asia would experience a decrease in its OADR between 2050 and 2100. North Africa, Sub-Saharan Africa, and the Middle East are also regions where even the large uncertainties associated with what might happen in the second half of the century are not large enough to make us doubt the increases in OADRs there.

\section{Proportions of the Population 80+}

According to the figures in Table 4, about one percent of the world's population was $80+$ years old in 2000. The mean forecast is for this figure to rise to 4 percent in 2050 and to 11 percent in 2100. For most of the regions the period 2025 to 2050 is the one in which the increase in the proportion is the fastest. In 2050, the countries cluster into four groups, those with proportions of the population $80+$ of 4 percent or less (North Africa, Sub-Saharan Africa, Latin America, Central Asia, the Middle East, South Asia, and Pacific Asia), those with proportions around 8 percent (the China Region and European FSU), and those around 10 percent or higher (Eastern Europe, Western Europe, Japan/Oceania, and North America). By 2100, the average forecast shows that in the Japan/Oceania region around 27 percent of the population would be $80+$ years old. This figure is very imprecise, with the 80 percent confidence interval ranging from a modest 11 percent to an enormous 42 percent. 
Table 4. Probabilistic forecasts of global and regional proportions of populations 80+ years old. The main figures in the Table are means of 1,000 simulated futures. The figures in parentheses are 80 percent prediction intervals.

\begin{tabular}{|c|c|c|c|c|c|c|}
\hline & 2000 & 2010 & 2025 & 2050 & 2075 & 2100 \\
\hline \multirow[t]{2}{*}{ North Africa } & 0.005 & 0.0061 & 0.008 & 0.026 & 0.061 & 0.106 \\
\hline & $(0.005-0.005)$ & $(0.0061-0.0062)$ & $(0.007-0.009)$ & $(0.018-0.036)$ & $(0.03-0.102)$ & $(0.043-0.195)$ \\
\hline \multirow[t]{2}{*}{ Sub-Saharan Africa } & 0.003 & 0.0029 & 0.003 & 0.005 & 0.011 & 0.030 \\
\hline & $(0.003-0.003)$ & $(0.0028-0.0029)$ & $(0.003-0.003)$ & $(0.004-0.006)$ & $(0.007-0.015)$ & $(0.015-0.054)$ \\
\hline \multirow[t]{2}{*}{ North America } & 0.032 & 0.0297 & 0.038 & 0.091 & 0.129 & 0.180 \\
\hline & $(0.032-0.032)$ & $(0.029-0.0304)$ & $(0.031-0.045)$ & $(0.051-0.136)$ & $(0.057-0.205)$ & $(0.068-0.294)$ \\
\hline \multirow[t]{2}{*}{ Latin America } & 0.009 & 0.0096 & 0.013 & 0.040 & 0.078 & 0.117 \\
\hline & $(0.009-0.009)$ & $(0.0095-0.0097)$ & $(0.012-0.015)$ & $(0.025-0.06)$ & $(0.035-0.132)$ & $(0.043-0.214)$ \\
\hline \multirow[t]{2}{*}{ Central Asia } & 0.008 & 0.0099 & 0.010 & 0.031 & 0.071 & 0.116 \\
\hline & $(0.008-0.008)$ & $(0.0098-0.0101)$ & $(0.009-0.011)$ & $(0.02-0.046)$ & $(0.034-0.121)$ & $(0.046-0.206)$ \\
\hline \multirow[t]{2}{*}{ Middle East } & 0.005 & 0.0059 & 0.008 & 0.026 & 0.070 & 0.126 \\
\hline & $(0.005-0.005)$ & $(0.0058-0.0059)$ & $(0.007-0.009)$ & $(0.016-0.038)$ & $(0.032-0.12)$ & $(0.049-0.224)$ \\
\hline \multirow[t]{2}{*}{ South Asia } & 0.006 & 0.0066 & 0.009 & 0.021 & 0.050 & 0.100 \\
\hline & $(0.006-0.006)$ & $(0.0065-0.0067)$ & $(0.008-0.01)$ & $(0.015-0.029)$ & $(0.026-0.082)$ & $(0.042-0.183)$ \\
\hline \multirow[t]{2}{*}{ China Region } & 0.009 & 0.0130 & 0.019 & 0.077 & 0.143 & 0.181 \\
\hline & $(0.009-0.009)$ & $(0.0128-0.0132)$ & $(0.017-0.022)$ & $(0.051-0.109)$ & $(0.069-0.237)$ & $(0.071-0.325)$ \\
\hline \multirow[t]{2}{*}{ Pacific Asia } & 0.006 & 0.0081 & 0.013 & 0.038 & 0.072 & 0.119 \\
\hline & $(0.006-0.006)$ & $(0.008-0.0082)$ & $(0.011-0.014)$ & $(0.026-0.054)$ & $(0.035-0.124)$ & $(0.046-0.22)$ \\
\hline \multirow[t]{2}{*}{ Japan/Oceania } & 0.035 & 0.0460 & 0.078 & 0.144 & 0.208 & 0.268 \\
\hline & $(0.035-0.035)$ & $(0.0451-0.0469)$ & $(0.064-0.093)$ & $(0.084-0.212)$ & $(0.094-0.335)$ & $(0.111-0.422)$ \\
\hline \multirow[t]{3}{*}{ Western Europe } & 0.033 & 0.0368 & 0.049 & 0.116 & 0.167 & 0.221 \\
\hline & $(0.033-0.033)$ & $(0.0362-0.0375)$ & $(0.041-0.058)$ & $(0.069-0.174)$ & $(0.075-0.268)$ & $(0.088-0.366)$ \\
\hline & 0.000 & 0.013 & 0.141 & 0.339 & 0.453 & 0.470 \\
\hline \multirow[t]{2}{*}{ Eastern Europe } & 0.019 & 0.0307 & 0.040 & 0.097 & 0.181 & 0.205 \\
\hline & (0.019-0.019) & $(0.0303-0.0311)$ & $(0.034-0.046)$ & $(0.061-0.14)$ & $(0.086-0.296)$ & $(0.081-0.356)$ \\
\hline \multirow[t]{2}{*}{ European FSU } & 0.020 & 0.031 & 0.034 & 0.084 & 0.152 & 0.162 \\
\hline & $(0.02-0.02)$ & (0.0303-0.0309) & $(0.03-0.038)$ & $(0.055-0.122)$ & $(0.072-0.247)$ & $(0.063-0.292)$ \\
\hline \multirow[t]{2}{*}{ World } & 0.011 & 0.013 & 0.017 & 0.042 & 0.072 & 0.109 \\
\hline & $(0.011-0.011)$ & $(0.013-0.0134)$ & $(0.015-0.019)$ & $(0.028-0.06)$ & $(0.036-0.116)$ & $(0.048-0.19)$ \\
\hline
\end{tabular}


The large uncertainties associated with the proportions $80+$ are a reflection of the inclusion of mortality uncertainty in our probabilistic forecasts. It is impossible to make sensible forecasts of the likely paths of ageing without it. We demonstrate this in Figure 6, where we show the predicted distribution of the proportions 80+ for Western Europe from 2000 to 2050. On the right-hand side of the graph, we mark the proportions in 2050 derived from the UN low and high variants. The low (high) variant produces a higher (lower) proportion 80+ because it assumes lower (higher) fertility. The difference between the proportions $80+$ based on the low and high variants are much smaller than one would expect from our predicted distribution because our forecasts incorporate mortality uncertainty. Our mean proportion $80+$ is higher than the UN's because by the end of the century, our fertility forecasts are generally lower than the UN's and our life expectancies at birth are generally higher.

Even with the substantial uncertainty around the proportions $80+$, we can still use them. In most of the world's regions, those proportions will, with quite high probabilities, rise from 2010 to 2025 and then again to 2050. After 2050, the ratios are still likely to rise, but the large uncertainties preclude us from making a definite statement that they will.

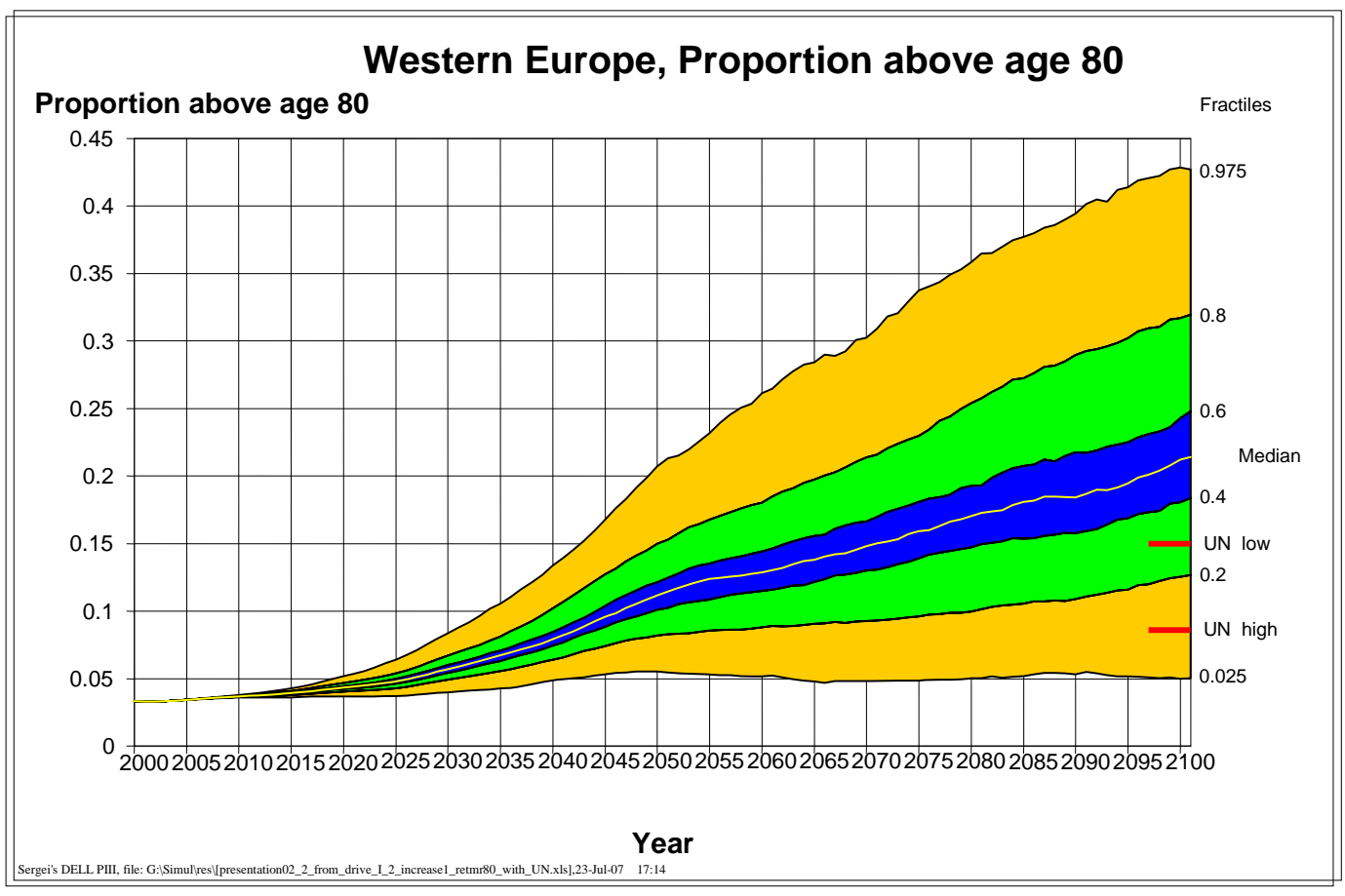

Figure 6. Forecasted distribution of the proportion of the population $80+$ years old in Western Europe, 2000 to 2100. 


\section{Average Ages}

Table 5 presents information on average ages. The average age of a person on Earth in 2000 was 29.7. Using the means of our forecasts, we expect that average to increase to 31.3 in 2010, to 34.3 in 2025, to 38.8 in 2050, and to 46.0 in 2100. The increase in average age over the century is around 16 years, and therefore the mean speed of increase is 1.6 years per decade. According to the mean forecast, we would not expect the speed to change much as the century progresses. The UN forecasts world life expectancy at birth to increase from 66.5 in 2005-10 to 75.1 in 2045-50, or at a rate of 2.15 years per decade. Therefore, average age is likely to be increasing more slowly than life expectancy. Average ages are slightly higher than median ages. As age structures become more symmetric over time, median ages converge to average ages. For the world, the difference between our average age and the UN median age in 2025 is 1.4 years. In 2050, the difference shrinks to 1.0 years.

An interesting comparison in the Table is between North America and European FSU. In 2000 and in 2100 their average ages are similar, but their paths of ageing are quite different. In the first half of the century, ageing is considerably more rapid in European FSU. In 2050, the means of the average age distributions differ by 5.6 years. After 2050, ageing in European FSU essentially comes to a halt. The average ages in 2050 and 2100 are virtually the same, and are indistinguishable once uncertainty is taken into account. In North America, there is no ageing hiatus. The average age is likely to increase throughout the second half of the century, eventually catching up to the European FSU region by 2100.

Currently, the area with the fastest increase in average age is the China Region. There the average age is expected to increase from 31.2 in 2000 to around 40.5 in 2025. The slowest increase is in Sub-Saharan Africa, where the average age is hardly expected to increase at all from 2000 to 2025. Over the entire century, the region with the largest increase in average age is the Middle East where the increase is 22.8 years. 
Table 5. Probabilistic forecasts of global and regional average ages of the population. The main figures in the Table are means of 1,000 simulated futures. The figures in parentheses are 80 percent prediction intervals.

\begin{tabular}{|c|c|c|c|c|c|c|}
\hline & 2000 & 2010 & 2025 & 2050 & 2075 & 2100 \\
\hline \multirow[t]{2}{*}{ North Africa } & 25.5 & 27.3 & 31.1 & 37.5 & 42.1 & 45.2 \\
\hline & (25.5-25.5) & $(27.1-27.6)$ & $(29.8-32.4)$ & (35.2-39.8) & $(38.8-45.7)$ & $(40.3-51)$ \\
\hline \multirow[t]{2}{*}{ Sub-Saharan Africa } & 22.1 & 21.6 & 22.9 & 27.4 & 33.0 & 38.3 \\
\hline & $(22.1-22.1)$ & $(21.2-22)$ & $(21.9-24)$ & $(25.5-29.7)$ & (30.6-35.7) & $(35.4-41.7)$ \\
\hline \multirow[t]{2}{*}{ North America } & 36.5 & 37.7 & 40.4 & 43.6 & 46.5 & 49.6 \\
\hline & $(36.5-36.5)$ & $(37.4-38.1)$ & $(39-41.7)$ & $(40.1-47)$ & $(41.4-51.6)$ & $(42.2-57.1)$ \\
\hline \multirow[t]{2}{*}{ Latin America } & 27.8 & 29.8 & 33.5 & 39.0 & 42.5 & 45.2 \\
\hline & $(27.8-27.8)$ & $(29.6-30)$ & $(32.3-34.7)$ & (36.4-41.9) & $(38.5-46.8)$ & $(39.6-51.7)$ \\
\hline \multirow[t]{2}{*}{ Central Asia } & 26.9 & 28.7 & 32.0 & 37.9 & 42.5 & 46.3 \\
\hline & $(26.9-26.9)$ & $(28.5-28.9)$ & $(30.8-33.3)$ & (35.5-40.5) & $(38.8-46.8)$ & $(40.9-52.1)$ \\
\hline \multirow[t]{2}{*}{ Middle East } & 24.2 & 26.0 & 29.8 & 37.1 & 42.9 & 47.0 \\
\hline & $(24.2-24.2)$ & $(25.8-26.3)$ & $(28.6-31.1)$ & (34.9-39.5) & (39.2-46.9) & $(41.2-53)$ \\
\hline \multirow[t]{2}{*}{ South Asia } & 26.5 & 27.8 & 31.0 & 37.0 & 42.8 & 47.8 \\
\hline & $(26.5-26.5)$ & $(27.5-28.2)$ & $(29.7-32.3)$ & (34.6-39.6) & $(39.5-46.4)$ & $(43.1-53)$ \\
\hline \multirow[t]{2}{*}{ China Region } & 31.2 & 35.1 & 40.5 & 47.9 & 50.9 & 51.9 \\
\hline & $(31.2-31.2)$ & $(34.7-35.6)$ & (39.3-41.7) & $(44.7-51.3)$ & $(45.2-56.9)$ & (44.6-60.3) \\
\hline \multirow[t]{2}{*}{ Pacific Asia } & 28.2 & 30.5 & 34.2 & 39.6 & 43.6 & 48.0 \\
\hline & $(28.2-28.2)$ & $(30.3-30.7)$ & (33.1-35.4) & $(37.1-42)$ & $(39.8-47.7)$ & $(42.6-54.4)$ \\
\hline \multirow[t]{2}{*}{ Japan/Oceania } & 40.4 & 43.0 & 46.9 & 51.4 & 54.4 & 57.8 \\
\hline & $(40.4-40.4)$ & $(42.8-43.3)$ & $(45.3-48.4)$ & (47.3-55.7) & $(47.4-62)$ & (48.4-67.6) \\
\hline \multirow[t]{2}{*}{ Western Europe } & 38.3 & 40.1 & 43.6 & 48.5 & 51.2 & 54.2 \\
\hline & $(38.3-38.3)$ & (39.9-40.3) & $(42.1-44.9)$ & $(44.7-52.4)$ & $(44.8-57.7)$ & $(45.9-63.2)$ \\
\hline \multirow[t]{3}{*}{ Eastern Europe } & 37.0 & 39.8 & 44.2 & 50.4 & 52.8 & 53.4 \\
\hline & $(37-37)$ & $(39.6-40.1)$ & $(42.9-45.6)$ & $(46.7-54.1)$ & $(46.4-59.8)$ & $(45.3-62.5)$ \\
\hline & 0.000 & 0.004 & 0.024 & 0.058 & 0.101 & 0.129 \\
\hline \multirow[t]{2}{*}{ European FSU } & 37.2 & 39.7 & 43.8 & 49.2 & 50.3 & 49.4 \\
\hline & $(37.2-37.2)$ & (39.5-39.9) & $(42.6-45.1)$ & $(45.6-52.8)$ & $(44.2-56.7)$ & $(42.5-57.8)$ \\
\hline \multirow[t]{2}{*}{ World } & 29.7 & 31.3 & 34.2 & 38.8 & 42.4 & 46.0 \\
\hline & $(29.7-29.7)$ & $(31-31.5)$ & $(33.1-35.3)$ & (36.4-41.4) & $(38.8-46.4)$ & $(41.1-51.4)$ \\
\hline
\end{tabular}




\section{New Measures of Ageing}

The future of ageing is uncertain because future trends in fertility, mortality, and migration are uncertain. But it is also far from certain whether our traditional measures of ageing are providing the best answers to the questions that we need asked. Traditional measures such as the proportion of the population $60+$ years old and the old age dependency ratio assume that people 60+ are old. But a 60 year old in 1900 might not be functionally the same as a 60 year old in 2000. By extension, a 60 year old in 2100 who could have a remaining life expectancy of 40 years may not be effectively as old as a 60 year old in 2000. Whether people are old in any meaningful way is not just a matter of the number of birthdays that they have experienced. In Sanderson and Scherbov (2005, 2006, 2007) and Lutz et al. (2008), we have presented new measures of ageing that take changes in life expectancy into account. We argue there that, in the long-run, being old is more closely related to the number of years people have left to live than it is to the number of years that they have currently lived.

Reformulating the way we measure ageing to take life expectancy change into account is not difficult. One way is to supplement the proportion of the population 60+ with the proportion of the population who are in age groups where remaining life expectancy is 15 years or less. We call this Prop. RLE 15-. Using the average forecast, the region in the world with the highest proportion of people 60+ in 2050 is Japan with 42.4 percent. In 2050, Japan is only the fourth oldest region if we consider people old when they get into age groups with remaining life expectancies of 15 years of less. The Prop. RLE 15- for Japan in 2050 is only 19.9 percent. In 2100, Japan again has the highest proportion of its population $60+$, but it is only the third highest region when we measure who is old using Prop. RLE 15-. Its Prop. RLE 15- in 2100 is less than 40 percent of its proportion 60+. Prop. RLE 15- for the world and our regions are shown in Table 6.

Prop. RLE 15- is only one of three new measures of ageing that we discussed in Lutz et al. (2008). One new measure adjusts median ages for changes in life expectancies (Sanderson and Scherbov 2005) and another one computes the average remaining life expectancy of population members. These three new measures provide a complementary view of the ageing process. Whether the conventional measures or the new ones are preferable depends on the details of what the researcher wishes to accomplish. 
Table 6. Global and regional proportions of populations in age groups with remaining life expectancy of 15 years or less. Figures in the Table are means of 1,000 simulated futures.

\begin{tabular}{lrrrr}
\hline & 2000 & 2010 & 2050 & 2100 \\
\hline North Africa & 5 & 5 & 10.8 & 15.8 \\
Sub Saharan Africa & 4.8 & 4.8 & 5.4 & 13.4 \\
North America & 11.3 & 9.7 & 13.6 & 15 \\
Latin America & 5.9 & 5.9 & 11.8 & 14.4 \\
Central Asia & 6.2 & 5.5 & 10.5 & 15.7 \\
Middle East & 4.4 & 4.1 & 9 & 16.4 \\
South Asia & 6 & 6.2 & 11.4 & 19.3 \\
China Region & 7.4 & 8.2 & 20.7 & 22.2 \\
Pacific Asia & 5.8 & 6.5 & 13.7 & 17.2 \\
Japan/Oceania & 12.7 & 13.8 & 19.9 & 20.5 \\
Western Europe & 13.4 & 12.8 & 19 & 19 \\
Eastern Europe & 12.9 & 13 & 22.3 & 21.3 \\
European Former Soviet Union & 14.1 & 13.7 & 22.3 & 19.2 \\
World & 7.4 & 7.3 & 12 & 15.6 \\
\hline
\end{tabular}

\section{Conclusions}

The extent of ageing in the future is uncertain. This is for two main reasons. First, population age distributions are uncertain because we do not know the future paths of fertility, mortality, and migration. The second is because the concept of who is old itself is likely to change over time. The UN high, medium, and low variants do not take mortality uncertainty or migration uncertainty into account and they do not allow for the possibility that the definition of who is old could change over time. Because of these limitations, exclusive reliance on the UN variants can produce misleading results for ageing research.

Slowly, over the course of the century, the forces driving variations in the conventional ageing measures will be changing. In most regions of the world, we can see two quite distinct phases of ageing, a more rapid period of increase in ageing measures in the first half of the century and then a slowdown in the pace of increase. When we take the uncertainty in the ageing measures into account, we see that, in some regions, it is even possible that those measures will be lower in 2100 than in 2050.

There is, however, a deeper uncertainty. Conventional measures of ageing assume that people are categorized as "old" when they reach a certain age. But any fixed age, such as 60 or 65 is inappropriate when we wish to study ageing over a long period of time. A 60 year old might be considered elderly in 2000, but not in 2100. Two aspects of ageing need to be distinguished. Over time, there will be more elderly people in the world, but as life expectancy increases and medical care improves, older people of a given age will become more capable and they have longer remaining lifetimes. In many ways, they will act like younger people did some decades earlier. We have explored this issue in more detail in Sanderson and Scherbov $(2005,2007)$ and Lutz et al. (2008), where we presented measures of ageing adjusted for life expectancy change. In this last paper, we also considered changes in the speed of ageing. 
In the past, demographers have had the good fortune of being able to study ageing using measures with fixed age boundaries. Ages around 60 and 65 coincided with normal pension ages and typical retirement ages. Now that normal pension ages are changing and we are increasingly aware that people in their early and mid-60s are not necessarily elderly, we are likely to need new measures of ageing, including those with variable age boundaries.

It may seem that the vision that we are presenting is a complex one. Measuring and understanding the movements and the uncertainties involved in our conventional measures of ageing as well as those associated with new measures that allow the age of becoming elderly to vary is certainly no easy task. In our view, in the past we have been looking at the analogue of a black and white picture of ageing. It is more complex to produce and analyse a picture in colour, but it is much more informative as well.

\section{References}

Bongaarts, J. 2006. How long do we live? Population and Development Review 32(4): 605-626.

Keyfitz, N. 1981. The limits of population forecasting. Population and Development Review 7(4): 579-593.

Kirk, D. 1996. Demographic transition theory. Population Studies 50(3): 361-387.

Lutz, W., W. Sanderson, and S. Scherbov. 2001a. The end of world population growth. Nature 412(6846): 543-545.

Lutz, W., S. Scherbov, and C. van Aardt. 2001b. South Africa's Uncertain Demographic Present and Future. Interim Report IR-01-019. Laxenburg, Austria: International Institute for Applied Systems Analysis.

Lutz, W., W. Sanderson, and S. Scherbov. 2004. The end of world population growth. Pages 17-83 in W. Lutz, W. Sanderson, and S. Scherbov (eds.), The End of World Population Growth in the $21^{\text {st }}$ Century: New Challenges for Human Capital Formation and Sustainable Development. London: Earthscan.

Lutz, W., W. Sanderson, and S. Scherbov. 2008. The coming acceleration of global population ageing. Nature 451(7179): 716-719.

Lutz, W., S. Scherbov, G.Y. Cao, Q. Ren, and X. Zheng. 2005. China’s Uncertain Demographic Present and Future. Interim Report IR-05-043. Laxenburg, Austria: International Institute for Applied Systems Analysis.

Notestein, F. 1945. Population: In the long view. Pages 36-57 in T. Schultz (ed.), Food for the World. Chicago: University of Chicago Press.

Oeppen, J. and J. Vaupel. 2002. Broken limits to life expectancy. Science 296(5570): 1029-1031.

Sanderson, W. and S. Scherbov. 2005. Average remaining lifetimes can increase as human populations age. Nature 435(7043): 811-813.

Sanderson, W. and S. Scherbov. 2006. A new perspective on population aging. Demographic Research 16: 27-58. 
Sanderson, W. and S. Scherbov. 2007. A near electoral majority of pensioners: Prospects and polices. Population and Development Review 33(3): 543-554.

United Nations. 1999. The World at Six Billion. New York: United Nations.

United Nations. 2007. World Population Ageing, 2007. New York: United Nations.

United Nations. 2008. World Population Prospects: The 2006 Revision, Volume 1, Comprehensive Tables. New York: United Nations. 


\section{Appendix}

The forecasts in this paper have resulted from updating forecasts that we previously published (Lutz et al. 2001a). Those forecasts, like the present ones, used 2000 as a base year. The updating process was a bit different for the China Region, Sub-Saharan Africa, and South Asia than for the other regions. In all the other regions, we used observed values of fertility, mortality, and migration in the period from 2000 to 2005. For the China Region, we used observed values of mortality and migration, but there were no reliable fertility data to use. The population of the China Region is dominated by the population of China. The other countries in the region are Cambodia, Laos, Mongolia, North Korea, and Vietnam. Published total fertility rates for China in that period range from 1.2 to 1.8. After a careful review of 18 different estimates (Lutz et al. 2005), we decided that the China Region's fertility, even in 2000, was uncertain and we assumed a distribution of total fertility rates at that date with a mean of 1.5 and an 80 percent uncertainty range of 1.3 to 1.7 . There are reasons to suspect that there are also uncertainties in the starting total fertility rates in Sub-Saharan Africa and South Asia (see for example Lutz et al. 2001b). Our fertility assumptions for selected years and their uncertainties are given in Appendix Table 1. Because of these baseline uncertainties in total fertility rates, we began our forecasts from the year 2000.

Mean life expectancies at birth are usually assumed to increase by two years per decade. The uncertainties around the means are assumed to grow over time, so that there remains a 10 percent chance in each year that life expectancy is lower than it was at the beginning of the century. The mortality rates are based on those in Lutz et al. (2001a) updated using observations from 2000 through 2005. The earlier mortality rate assumptions can be found in Lutz et al. (2004: 26, Table 2.2).

Justifications of our assumptions and a complete description of the methodology that we used in making the forecasts can be found in Lutz et al. (2004). 
Appendix Table 1. Mean total fertility rate assumptions and 80 percent probability intervals (in parentheses) for selected years. Sources for 2000, 2025, 2050 from Lutz et al. (2008: Supplementary Material, Supplementary Table 3); for 2082 from Lutz et al. (2004: 25, Table 2.1). Note: The year 2082 is used here because it is assumed that after that date the means and standard deviations of fertility rates remain constant.

\begin{tabular}{lcccc}
\hline Region/Year & 2000 & 2025 & 2050 & 2082 \\
\hline North Africa & 3.3 & 2.2 & 2.0 & 1.9 \\
Sub-Saharan Africa & & $(1.8-2.6)$ & $(1.7-2.4)$ & $(1.4-2.4)$ \\
& 5.6 & 3.4 & 2.6 & 1.8 \\
North America & $(5.3-5.8)$ & $(2.7-4.1)$ & $(2.1-3.2)$ & $(1.3-2.3)$ \\
& 2.0 & 1.9 & 1.9 & 2.0 \\
Latin America & & $(1.5-2.2)$ & $(1.6-2.2)$ & $(1.5-2.5)$ \\
& 2.6 & 2.1 & 2.1 & 2.0 \\
Central Asia & & $(1.8-2.5)$ & $(1.7-2.4)$ & $(1.5-2.5)$ \\
& 2.8 & 2.2 & 2.0 & 1.8 \\
Middle East & & $(1.8-2.6)$ & $(1.7-2.3)$ & $(1.3-2.3)$ \\
& 3.7 & 2.2 & 2.0 & 1.8 \\
South Asia & & $(1.8-2.6)$ & $(1.6-2.3)$ & $(1.3-2.3)$ \\
& 3.5 & 2.2 & 1.9 & 1.5 \\
China Region & $(3.3-3.6)$ & $(1.8-2.6)$ & $(1.5-2.2)$ & $(1.0-2.0)$ \\
& 1.5 & 1.4 & 1.5 & 1.7 \\
Pacific Asia & $(1.3-1.7)$ & $(1.1-1.7)$ & $(1.2-1.8)$ & $(1.2-2.2)$ \\
& 2.5 & 2.1 & 1.9 & 1.6 \\
Japan/Oceania & & $(1.8-2.5)$ & $(1.6-2.2)$ & $(1.1-2.1)$ \\
& 1.4 & 1.4 & 1.5 & 1.6 \\
Western Europe & & $(1.1-1.8)$ & $(1.2-1.8)$ & $(1.1-2.1)$ \\
Eastern Europe & 1.7 & 1.5 & 1.6 & 1.7 \\
& & $(1.2-1.9)$ & $(1.3-2.0)$ & $(1.2-2.2)$ \\
European FSU & 1.4 & 1.4 & 1.6 & 1.7 \\
& & $(1.1-1.8)$ & $(1.3-2.0)$ & $(1.2-2.2)$ \\
\hline
\end{tabular}

